\title{
Erratum: Better living through microbes
}

Monya Baker

Nat. Biotechnol. 23, 645-647 (2005)

On page 646, Table 1, last column, the status of the Osel bacteriotherapy Clostridium butyricum was given as "Phase 2 trial." It should have read, "Phase $2 / 3$ trial (US) planned."

On page 647 , column 2, last paragraph, line 16 , “... a tumor marker present in many ovarian and prostate cancers...” should have read "a tumor marker present in many ovarian and pancreatic cancers...." Prostate cancers should have been pancreatic cancers. In the last line of the same خे paragraph, "EphsA2 antigen" should have been "EphA2 antigen."

\section{Erratum: Leaders and laggards in the stem cell enterprise}

\section{Stephan Herrera}

Nat. Biotechnol. 23, 775-777 (2005)

On page 776, column 3, paragraph 3, line 8, one of the recipients of the Starr Foundation gift for stem cell research was reported to be Rochester University; it should have read Rockefeller University.

\section{Corrigendum: The origins of new drugs}

\section{Robert Kneller}

Nat. Biotechnol. 23, 529-530 (2005)

On page 528, an imaging agent, Prussian Blue, was mistakenly included in the NME totals for 2003. Thus, in Table 1 and corresponding places in the text, the total number of NMEs approved in 2003 should be reduced from 21 to 20 and the total number of new drugs from 27 to 26 . The totals for the 6-year period should be similarly reduced from 145 to 144 for total NMEs and from 171 to 170 for total drugs. Also, the NME Somavert originated in Ohio University, which then licensed rights to Genentech. Thus, the number of university inventions should be increased from 3 to 4 for 2003 , and from 20 to 21 for the entire 6-year period.

\section{Corrigendum: National origins of new drugs}

\section{Robert Kneller}

Nat. Biotechnol. 23, 655-656 (2005)

On page 655, in calculating the nonpharma portion of NMEs in Table 1, errors arose because in the case of two of the drugs that were attributed 